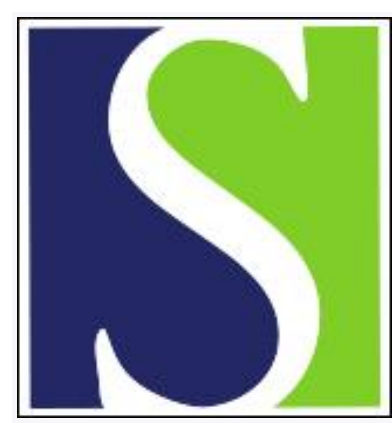

Scand J Work Environ Health 1999;25(3):233-237

https://doi.org/10.5271/sjweh.429

Issue date: Jun 1999

Effect of ethanol on the urinary excretion of cyclohexanol and cyclohexanediols, biomarkers of the exposure to cyclohexanone, cyclohexane and cyclohexanol in humans by Mráz J, Gálová E, Nohová H, Vítková D, Tichý M

Key terms: biological monitoring; metabolic interference

This article in PubMed: www.ncbi.nlm.nih.gov/pubmed/10450774

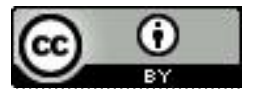




\title{
Effect of ethanol on the urinary excretion of cyclohexanol and cyclohexanediols, biomarkers of the exposure to cyclohexanone, cyclohexane and cyclohexanol in humans
}

\author{
by Jaroslav Mráz, PhD, ${ }^{1}$ Eva Gálová, ${ }^{1}$ Hana Nohová, ${ }^{1}$ Dana Vítková, ${ }^{1}$ Miloñ Tichý, DSc ${ }^{1}$
}

\begin{abstract}
Mráz J, Gálová E, Nohová H, Vítková D, Tỉchý M. Effect of ethanol on the urinary excretion of cyclohexanol and cyclohexanediols, biomarkers of the exposure to cyclohexanone, cyclohexane and cyclohexanol in humans. Scand J Work Environ Health 1999;25(3):233-237.
\end{abstract}

\begin{abstract}
Objectives This study explored the acute effect of ethanol (EtOH) on the urinary excretion of cyclohexanol (CHol), 1,2-and 1,4-cyclohexanediol ( $\mathrm{CH}$-diol), biomarkers of exposure to important solvents, and chemical intermediates cyclohexanone ( $\mathrm{CH}-0$ e) , cyclohexane $(\mathrm{CH})$ and cyclohexanol.

Methods Volunteers (5-8 in each group) were exposed for 8 hours either to $\mathrm{CH}$-one, $\mathrm{CH}$ or $\mathrm{CH}$-ol vapor at concentrations of about 200,1000 , and $200 \mathrm{mg} / \mathrm{m}^{3}$, respectively, with concomitant ingestion of EtOH (4 14-g doses taken during the exposure). Urine was collected for 72 hours and analyzed for $\mathrm{CH}-\mathrm{ol}$ and $\mathrm{CH}$-diols using a procedure involving acidic hydrolysis and gas chromatographic determination.

Results The metabolic yields of $\mathrm{CH}-\mathrm{ol}, 1,2-$, and 1,4-CH-diol, respectively, in the exposures with EtOH were as follows: $11.3 \%, 36 \%, 23 \%$ after the exposure to $\mathrm{CH}-$ one, $3.1 \%, 15 \%, 8 \%$ after the exposure to $\mathrm{CH}$, and $6.6 \%, 24 \%$, $18 \%$ after the exposure to $\mathrm{CH}$-ol. [The corresponding values obtained previously in matching experiments without EtOH were as follows: $1.0 \%, 39 \%, 18 \%(\mathrm{CH}-o n e) ; 0.5 \%, 23 \%, 11 \%(\mathrm{CH})$; and $1.1 \%, 19 \%, 8 \%(\mathrm{CH}-\mathrm{ol})$.] The excretion curves of the metabolites in the exposures with EtOH were not delayed when compared with the corresponding curves of a comparison group.

Conclusions The urinary excretion of $\mathrm{CH}$-diols is much less sensitive to EtOH than that of $\mathrm{CH}$-ol. It is recommended to employ $\mathrm{CH}$-diols as useful and more reliable biomarkers of exposure to $\mathrm{CH}$-one, $\mathrm{CH}$ and $\mathrm{CH}$-ol in field examinations.
\end{abstract}

Key terms biological monitoring, metabolic interference.

In our previous papers on the human metabolism of the important solvents and chemical intermediates cyclohexanone (CH-one), cyclohexane $(\mathrm{CH})$ and cyclohexanol $(\mathrm{CH}$-ol), we demonstrated that 1,2- and 1,4-cyclohexanediol (CH-diol) are major urinary metabolites and useful new biomarkers of exposure to each of the title compounds $(1,2)$. Hitherto, biomonitoring of $\mathrm{CH}$-one and $\mathrm{CH}$ has been based solely on the determination of a minor metabolite, $\mathrm{CH}-\mathrm{ol}(3-5)$.

Acute ethanol (EtOH)-induced effects on the metabolism of other xenobiotics, based on the inhibition of alcohol dehydrogenase (ADH) or the microsomal oxidative system $\mathrm{P} 450$ involved in the biotransformation of numerous organic compounds, is a well known phenomenon. The consumption of alcoholic beverages shortly before or during a workshift (or in model laboratory experiments) modifies urinary levels of metabolites of styrene (6), xylenes (7), trichloroethylene (8) and other solvents significantly. As to $\mathrm{CH}$-one, $\mathrm{CH}$, or $\mathrm{CH}$-ol, the reduction of $\mathrm{CH}$-one to $\mathrm{CH}$-ol (the primary step in the metabolism of $\mathrm{CH}$-one) is catalyzed by $\mathrm{ADH}(9)$, while the oxidation of $\mathrm{CH}$ to $\mathrm{CH}$-ol (the primary step in the metabolism of $\mathrm{CH}$ ) is mediated by the $\mathrm{P} 450$ system enzymes (10). The enzymes responsible for the subsequent oxidation of $\mathrm{CH}$-ol to $\mathrm{CH}$-diols have not, as yet, been identified, but they are likely to belong to the P450 enzymes, too. Thus interference of EtOH with the metabolism of $\mathrm{CH}-\mathrm{one}, \mathrm{CH}$, and $\mathrm{CH}-\mathrm{ol}$ can be anticipated.

In this study, the effect of EtOH on the urinary excretion of $\mathrm{CH}$-ol and $\mathrm{CH}$-diols following exposures to

1 National Institute of Public Health, Centre of Industrial Hygiene and Occupational Diseases, Prague, Czech Republic.

Reprint requests to: Dr Jaroslav Mráz, National Institute of Public Health, Šrobárova 48, 10042 Prague 10, Czech Republic. 
$\mathrm{CH}$-one, $\mathrm{CH}$, or $\mathrm{CH}-\mathrm{ol}$ vapor was evaluated for human volunteers.

\section{Subjects and methods}

\section{General design}

The experiments and methods employed were basically those used in our previous studies $(1,2)$. Volunteers were exposed under defined conditions either to $\mathrm{CH}$-one, $\mathrm{CH}$, or $\mathrm{CH}$-ol vapor at concentrations close to the respective occupational exposure limits with concomitant ingestion of EtOH. Their urine was collected and analyzed for $\mathrm{CH}-$ ol, 1,2-, and 1,4-CH-diol. The results were compared with those obtained previously in matching experiments without $\mathrm{EtOH}$.

\section{Subjects}

Four women and 5 men, aged 32 to 54 years, volunteered to participate in the experiments. Most of them took part in the previous investigations $(1,2)$, from which the reference data used in this study were obtained. The scheme of participation of the subjects in the exposure experiments is shown in table 1.

All the subjects were healthy and showed no abnormalities in routine clinical examinations, none of them admitted having an excessive drinking habit or drug abuse, and none of them drank alcohol (except for the defined experimental doses) or took medicine 1 day before or during the collection of urine. The experiments were conducted with informed consent according to the recommendations of the Declaration of Helsinki (11) and were approved by the Scientific Committee of the Czech Ministry of Health.

Table 1. Scheme of participation of the subjects in the exposure experiments. $(\mathrm{CH}$-one $=$ cyclohexanone, $\mathrm{CH}=$ cyclohexane, $\mathrm{CH}$ $\mathrm{ol}=$ cyclohexanol, $\mathrm{EtOH}=$ ethanol,$+=$ participation)

\begin{tabular}{|c|c|c|c|c|c|c|c|}
\hline \multirow[t]{3}{*}{ Subject } & \multirow[t]{3}{*}{ Gender } & \multicolumn{6}{|c|}{ Exposure } \\
\hline & & \multicolumn{2}{|c|}{$\mathrm{CH}$-one } & \multicolumn{2}{|c|}{$\mathrm{CH}$} & \multicolumn{2}{|c|}{$\mathrm{CH}-0 \mathrm{l}$} \\
\hline & & $\begin{array}{l}\text { Withouta } \\
\text { EtOH }\end{array}$ & $\begin{array}{l}\text { With } \\
\text { EtOH }\end{array}$ & $\begin{array}{c}\text { Without }{ }^{b} \\
\text { EtOH }\end{array}$ & $\begin{array}{l}\text { With } \\
\text { EtOH }\end{array}$ & $\begin{array}{c}\text { Withoutb } \\
\text { EtOH }\end{array}$ & $\begin{array}{l}\text { With } \\
\text { EtOH }\end{array}$ \\
\hline 1 & Female & + & + & + & + & + & + \\
\hline 2 & Female & + & + & + & + & + & + \\
\hline 3 & Female & + & + & + & + & + & + \\
\hline 4 & Female & + & + & + & + & + & + \\
\hline 5 & Male & + & + & + & + & + & + \\
\hline 6 & Male & + & + & + & & + & \\
\hline 7 & Male & & + & + & & + & + \\
\hline 8 & Male & & + & + & & + & + \\
\hline 9 & Male & + & & & & & \\
\hline 10 & Male & + & & & & & \\
\hline 11 & Male & & & & & & $t$ \\
\hline
\end{tabular}

a Control, carried out previously and described in reference 1.

b Control, carried out previously and described in reference 2.

\section{Exposures}

The exposures to the vapor of the $\mathrm{CH}$ compounds were conducted with groups of 2 to 4 subjects in a closed exposure chamber (volume, $64 \mathrm{~m}^{3}$ ) with automatic maintenance of the vapor concentration, as described previously $(1,2)$. In brief, the calculated amounts of liquid $\mathrm{CH}$-one, $\mathrm{CH}$, or $\mathrm{CH}-\mathrm{ol}$ were evaporated before the exposure, and further vapor supply was controlled by feedback from a Carlo Erba gas chromatograph equipped with an automatic gas-sampling valve, analyzing the atmosphere at 5 -minute intervals. The analyses were performed on a stainless steel column $(0.5 \mathrm{~m} \times 5 \mathrm{~mm})$ filled with $20 \%$ Carbowax 20M on silanized Gas Chrom P and operating at $50^{\circ} \mathrm{C}(\mathrm{CH})$ or $100^{\circ} \mathrm{C}(\mathrm{CH}$-one, $\mathrm{CH}$-ol). The coefficient of variation of the concentration measurements during the exposures ranged from $4 \%$ to $9 \%$. The mean temperature and relative humidity during the exposures were $26^{\circ} \mathrm{C}$ and $65 \%$, respectively.

All the exposures were conducted over a period of 8 hours (from 0800 to 1600 ).

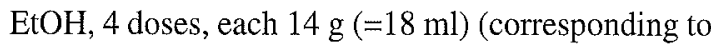
the EtOH content of 0.51 of weak beer), diluted with orange juice, was ingested at $0900,1100,1300$, and 1500 during the inhalation exposures or at $1600,1800,2000$, and 2200 after the $\mathrm{CH}$-one exposure. The subjects were at rest during the exposures. They left the exposure chamber at 2-hour intervals for $2-3$ minutes to void urine.

The exposures with EtOH were performed within 12 months after the matching control experiments.

\section{Measurement of pulmonary ventilation and retention in the respiratory tract}

Minute respiratory volume was measured by Wright respirometers 12 times at 10 -minute intervals, regularly spread throughout the exposure. Mean retention in the respiratory tract ( $\mathrm{r}$ ) was calculated from the vapor concentration in exhaled $\left(\mathrm{C}_{\mathrm{e}}\right)$ and inhaled $\left(\mathrm{C}_{\mathrm{i}}\right)$ air: $\mathrm{r}(\%)=$ $100\left(1-\mathrm{C}_{\mathrm{c}} / \mathrm{C}_{\mathrm{i}}\right)$. The analysis of the mean exhaled air, which was conducted 4 times throughout the exposure (in about 1, 3, 5 and $7 \mathrm{~h}$ ) for each subject, consisted of forcing the breath through a metal tube into a 7-1 silanized glass vessel, where it was passively mixed and then withdrawn by continuous suction into a manually operated sampling valve of the gas chromatograph. Inhaled ambient air was measured simultaneously using an automatic sampling valve.

\section{Analysis of the urine}

Urine (18 samples per person per experiment, see figures $1-3$ ) was collected for 72 hours and kept frozen until the analysis. $\mathrm{CH}-\mathrm{ol}, 1,2-$, and 1,4-CH-diol were determined by the gas chromatographic method of Flek \& Šedivec $(1,12)$. The standard procedure involved acidic hydrolysis of the glucuronide conjugates. Therefore, each 
determined compound represented the sum of its conjugated and unconjugated forms.

\section{Results}

The ingestion of EtOH in 4 doses, $14 \mathrm{~g}$ each, during 8hour inhalation exposures to $\mathrm{CH}$-one, $\mathrm{CH}$, and $\mathrm{CH}$-ol at concentrations close to the occupational exposure limits $\left(200,1050\right.$ and $200 \mathrm{mg} / \mathrm{m}^{-3}$, respectively) interfered with the metabolism of these compounds. The most striking effect was a several-fold increase in the yield of urinary $\mathrm{CH}$-ol as compared with the exposures without $\mathrm{EtOH}$ (expressed as the percentage of the absorbed dose of the parent compound), from $1.0 \%$ to $11.3 \%$ (CH-one), from $0.5 \%$ to $3.1 \%(\mathrm{CH})$, and from $1.1 \%$ to $6.6 \%(\mathrm{CH}-\mathrm{ol})$, respectively. The metabolic yields of $\mathrm{CH}$-diols were affected by EtOH to a much smaller extent, being almost
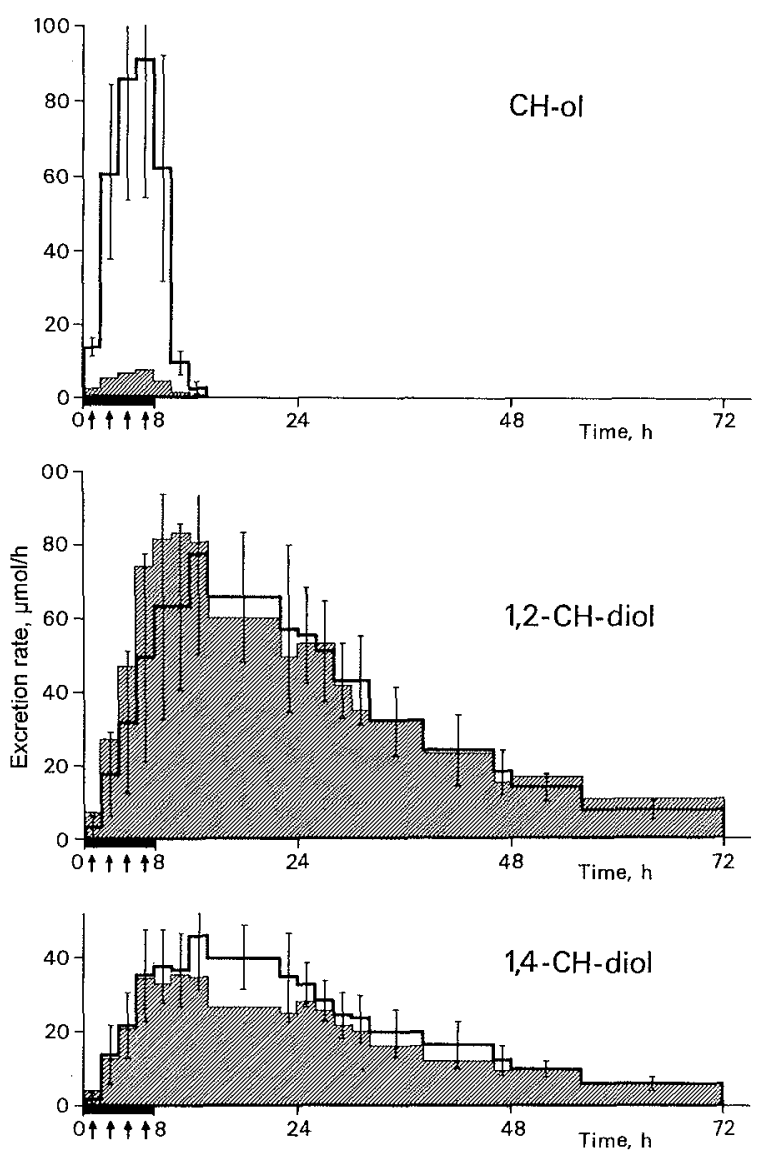

Figure 1. Urinary excretion of cyclohexanol $(\mathrm{CH}-\mathrm{ol}), 1,2$-cyclohexanediol (1,2-CH-diol), and 1,4-cyclohexanediol (1,4-CH-diol) after a single 8-hour exposure to cyclohexanone (CH-one) vapor (189 mg/ $\mathrm{m}^{3}$ ) with concomitant ingestion of $414-\mathrm{g}$ doses of ethanol (EtOH) (arrows). Hatched diagram is for the control exposure to $\mathrm{CH}$-one, 207 $\mathrm{mg} / \mathrm{m}^{3}$, carried out previously (1). Bars indicate the standard deviations for 8 subjects (shown only for the exposure with EtOH). unchanged in the case of $\mathrm{CH}$-one, decreased in the case of $\mathrm{CH}$, and increased in the case of $\mathrm{CH}$-ol (table 2).

The excretion curves of $\mathrm{CH}-\mathrm{ol}$ and $\mathrm{CH}$-diols exhibited no EtOH-induced time shift of their maximums; nevertheless, the plots of 1,2-CH-diol appeared to be slightly flattened in the exposures with EtOH (figures 1-3).

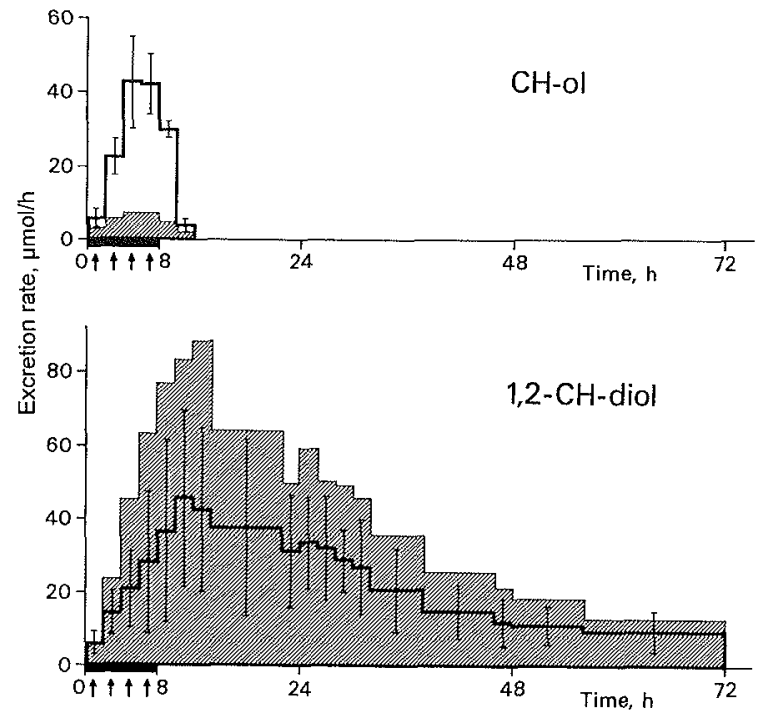

Figure 2. Urinary excretion of cyclohexanol $(\mathrm{CH}-0 \mathrm{l})$ and 1,2-cyclohexanediol (1,2-CH-diol) after a single 8-hour exposure to cyclohexane (CH) vapor $\left(1005 \mathrm{mg} / \mathrm{m}^{3}\right)$ with concomitant ingestion of $414-\mathrm{g}$ doses of ethanol (EtOH) (arrows). The hatched diagram is for the control exposure to $\mathrm{CH}, 1010 \mathrm{mg} / \mathrm{m}^{3}$, carried out previously (2). Bars indicate the standard deviations for 5 subjects (shown only for the exposure with EtOH).

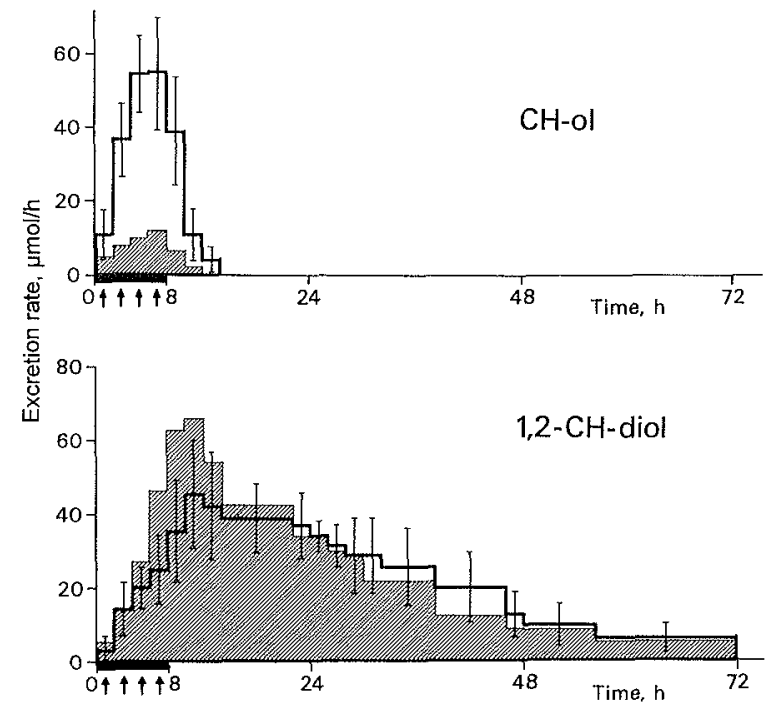

Figure 3. Urinary excretion of cyclohexanol ( $\mathrm{CH}-\mathrm{ol})$ and 1,2-cyclohexanediol $(1,2-\mathrm{CH}$-diol) after a single 8-hour exposure to $\mathrm{CH}$-ol vapor $\left(186 \mathrm{mg} / \mathrm{m}^{3}\right)$ after concomitant ingestion of $414-\mathrm{g}$ doses of ethanol (EtOH) (arrows). The hatched diagram is for the control exposure to $\mathrm{CH}-0$ l, $236 \mathrm{mg} / \mathrm{m}^{3}$, carried out previously (2). Bars indicate the standard deviations for 8 subjects (shown only for the exposure with EtOH). 
Table 2 . Mass balance of cyclohexanone $(\mathrm{CH}-\mathrm{one})$, cyclohexane $(\mathrm{CH})$ and cyclohexanol $(\mathrm{CH}-\mathrm{ol})$ in humans after 8 hours of inhalation exposure with concomitant ingestion of $414-\mathrm{g}$ doses of ethanol $(\mathrm{EtOH})$. The data in italics are from control exposures carried out previously. (1,2-CH-diol =1,2-cyclohexanediol, 1,4-CH-diol = 1,4-cyclohexanediol)

\begin{tabular}{|c|c|c|c|c|c|c|c|c|c|c|c|c|c|c|c|}
\hline \multirow[t]{3}{*}{ Compound(s) } & \multirow[t]{3}{*}{$N$} & \multirow{2}{*}{\multicolumn{2}{|c|}{$\begin{array}{l}\text { Concentration } \\
\text { in air }\left(\mathrm{mg} / \mathrm{m}^{3}\right)\end{array}$}} & \multirow{2}{*}{\multicolumn{2}{|c|}{$\begin{array}{c}\text { Minute } \\
\text { respiratory } \\
\text { volume }(1 / \mathrm{min})\end{array}$}} & \multirow{2}{*}{\multicolumn{2}{|c|}{$\begin{array}{l}\text { Retention } \\
\text { in respiration } \\
\text { tract }(\%)\end{array}$}} & \multirow{2}{*}{\multicolumn{2}{|c|}{$\begin{array}{c}\text { Total } \\
\text { absorbed } \\
\text { dose } \\
\text { (mmol) }\end{array}$}} & \multicolumn{6}{|c|}{$\begin{array}{l}\text { Proportion (\%) of the dose } \\
\text { excreted in urine during } 72 \mathrm{~h}\end{array}$} \\
\hline & & & & & & & & & & \multicolumn{2}{|c|}{$\mathrm{CH}-\mathrm{Ol}$} & \multicolumn{2}{|c|}{ 1,2-CH-diol } & \multicolumn{2}{|c|}{ 1,4-CH-diol } \\
\hline & & Mean & SD & Mean & SD & Mean & SD & Mean & SD & Mean & SD & Mean & SD & Mean & SD \\
\hline \multicolumn{16}{|l|}{$\mathrm{CH}$-one } \\
\hline With EtOH & 8 & 189 & 17 & 11.5 & 2.3 & 58.3 & 3.6 & 6.11 & 1.12 & 11.3 & 3.3 & 35.9 & 6.0 & 22.9 & 2.5 \\
\hline Without EtOH & 8 & 207 & 3 & 11.0 & 2.3 & 58.1 & 1.3 & 6.42 & 1.20 & 1.0 & 0.3 & 38.5 & 5.3 & 18.2 & 2.1 \\
\hline \multicolumn{16}{|l|}{$\mathrm{CH}$} \\
\hline With $\mathrm{EtOH}$ & 5 & 1005 & & 11.9 & 2.1 & 14.2 & 4.4 & 9.4 & 2.0 & 3.1 & 0.9 & 15.2 & 5.1 & 7.9 & 1.9 \\
\hline Without EtOH & 8 & 1010 & 35 & 10.8 & 2.5 & 18.4 & 3.9 & 11.1 & 1.0 & 0.5 & 0.2 & 23.4 & 4.2 & 11.3 & 2.9 \\
\hline \multicolumn{16}{|l|}{$\mathrm{CH}-\mathrm{Ol}$} \\
\hline With EtOH & 8 & 186 & 5 & 11.5 & 1.3 & 63.8 & 2.3 & 6.50 & 0.62 & 6.6 & 1.2 & 24.1 & 4.9 & 18.0 & 2.9 \\
\hline Without EtOH ${ }^{c}$ & 8 & 236 & 2 & 11.7 & 2.5 & 64.2 & 1.9 & 8.46 & 1.85 & 1.1 & 0.3 & 19.1 & 3.8 & 8.4 & 1.4 \\
\hline
\end{tabular}

a Calculated as a product of the concentration of the $\mathrm{CH}$ compound in the air, pulmonary ventilation during 8 hours, and retention in the respiratory tract.

b Control, data from reference 1 .

'Control, data from reference 2 .

The uptake of the parent $\mathrm{CH}$ compounds in the matching exposures with and without EtOH was not exactly the same (table 2). Therefore, the effect of $\mathrm{EtOH}$ on the excretion rate of $\mathrm{CH}$-ol and $\mathrm{CH}$-diols was not quantified by direct comparison of the values from matching experiments as plotted in figures $1-3$; instead a correction for differences in the uptake had to be included. Thus the comparison was made between excretion rates obtained in the experiments with and without $\mathrm{EtOH}$, the latter being multiplied by the ratio of uptakes in the exposures with and without $\mathrm{EtOH}$ (table 3).

The ingestion of EtOH (4 14-g doses) during a 6-hour period after the inhalation exposure to $\mathrm{CH}$-one resulted in a several-fold rise of urinary $\mathrm{CH}$-ol (figure 4), while

Table 3 Relative excretion rate of cyclohexanol ( $\mathrm{CH}-\mathrm{ol})$ and cyclohexanediols ( $\mathrm{CH}$-diol) in the last 2-hour period of 8-hour inhalation exposures to cyclohexanone ( $\mathrm{CH}$-one), cyclohexane (CH) and $\mathrm{CH}-\mathrm{Ol}$ with concomitant ingestion of $414-\mathrm{g}$ doses of ethanol (EtOH).

\begin{tabular}{|c|c|c|c|c|c|c|}
\hline \multirow[t]{3}{*}{ Compounds ${ }^{a}$} & \multicolumn{6}{|c|}{ Relative excretion rate ${ }^{b}(\%)$} \\
\hline & \multicolumn{2}{|c|}{$\mathrm{CH}-\mathrm{ol}$} & \multicolumn{2}{|c|}{ 1,2-CH-diol } & \multicolumn{2}{|c|}{ 1,4-CH-diol } \\
\hline & Mean & SD & Mean & SD & Mean & SD \\
\hline $\mathrm{CH}-$ one+EtOH & 1270 & 520 & 70 & 39 & 108 & 38 \\
\hline $\mathrm{CH}+\mathrm{EtOH}$ & 750 & 140 & 52 & 35 & 52 & 32 \\
\hline $\mathrm{CH}-\mathrm{OH}+\mathrm{EtOH}$ & 620 & 170 & 69 & 25 & 140 & 57 \\
\hline
\end{tabular}

a $\mathrm{CH}$-one, $189 \mathrm{mg} / \mathrm{m}^{3} ; \mathrm{CH}, 1010 \mathrm{mg} / \mathrm{m}^{3} ; \mathrm{CH}-0 \mathrm{l}, 186 \mathrm{mg} / \mathrm{m}^{3} ; \mathrm{EtOH}, 414-$ $\mathrm{g}$ doses taken $1,3,5$ and 7 hours after the start of the exposures to $\mathrm{CH}$ compounds.

D The relative excretion rates were calculated as the ratio of the corresponding excretion rates in matching experiments with and without EtOH, respectively, after correction for different uptakes of the parent $\mathrm{CH}$ compounds in the experiments. The excretion rates in the control experiments were designated as $100 \%$. no significant effect on the level of $\mathrm{CH}$-diols was observed (not shown).

\section{Discussion}

Numerous examples have been reported on the metabolic interactions of various xenobiotics with EtOH. The most common mechanism is the competition between EtOH and xenobiotics for ADH or the microsomal P450 oxidation system. Inhibition of the primary metabolic reaction produces an elevated blood level of the parent compound, paralleled by reduced excretion of the metabolites. The excretion rates of the metabolites can attain levels characteristic for control experiments after the elimination of EtOH from the organism, the excretion

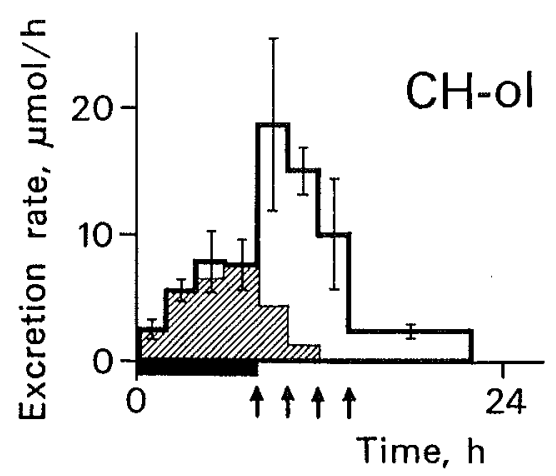

Figure 4. Urinary excretion of cyclohexanol $(\mathrm{CH}-\mathrm{Ol})$ after a single 8hour exposure to cyclohexanone ( $\mathrm{CH}-0 \mathrm{ne})$ vapor $\left(185 \mathrm{mg} / \mathrm{m}^{3}\right)$ with subsequent administration of $414-\mathrm{g}$ doses of ethanol (EtOH) (arrows). The hatched diagram is for the control exposure to $\mathrm{CH}-0$ ne, 207 $\mathrm{mg} / \mathrm{m}^{3}$, carried out previously (1). Bars indicate the standard deviations for 4 subjects (shown only for the exposure with $\mathrm{EtOH}$ ). 
peaks then being shifted for up to several hours. Similarly, inhibition occurring at a stage of a metabolic intermediate results in an accumulation of the intermediate in blood and increased elimination of this intermediate in urine. In some cases, the inhibitory effect of EtOH has been attributed not to competition for an active site of an enzyme but instead to competition for the cofactor NAD+ (nicotinamide adonine dinucleotide), which was depleted due to involvement in the ADH-mediated oxidation of $\mathrm{EtOH}$ (13). On the other hand, the increased concentration of the ADH-NADH complex, produced in the metabolism of EtOH, accounted for the EtOH-accelerated reduction of chloral hydrate (14) or $\mathrm{CH}$-one (13), mediated by $\mathrm{ADH}$ and requiring $\mathrm{NADH}$ (reduced form of nicotinamide adenine dinucleotide). Involvement of this mechanism was supported by the finding of the transfer of hydrogen between $\mathrm{CH}$-one and $\mathrm{EtOH}$ after their simultaneous administration (9). In vivo, faster decay of $\mathrm{CH}$-one and a faster rise of $\mathrm{CH}$-ol in blood were observed after the coadministration of $\mathrm{EtOH}$ and $\mathrm{CH}-$ one to rabbits (13).

In our present study, coadministration of $\mathrm{EtOH}$ with $\mathrm{CH}$-one, $\mathrm{CH}$, or $\mathrm{CH}$-ol modified the metabolism of all the parent compounds in a similar manner. The uniform several-fold increase in urinary $\mathrm{CH}$-ol indicates that inhibition occurs at a metabolic step common to each of the title compounds (ie, oxidation of $\mathrm{CHol}$ ). On the other hand, the overall production of $\mathrm{CH}$-diols was not affected by EtOH as dramatically, perhaps due to compensation of the inhibition by an elevation of the blood level of CH-ol. The observed slight differences in the effect of EtOH on the metabolism of each particular CH compound are difficult to interpret unless more detailed knowledge on the kinetics of relevant partial reactions becomes available. The aforementioned reactions include (i) oxidation of $\mathrm{CH}$ to $\mathrm{CH}-\mathrm{ol}$, (ii) reduction of $\mathrm{CH}$-one to $\mathrm{CH}$-ol, (iii) oxidation of $\mathrm{CH}$-ol to $\mathrm{CH}$-diols, and (iv) side reactions. The occurrence of the last one is only deduced from the finding that the amounts of excreted $\mathrm{CH}$ ol and CH-diols accounted for not more than $30 \%$ to $60 \%$ of the absorbed parent compounds. There is also an indication that $\mathrm{CH}$-diols undergo reactions other than the conjugations since, after ingestion of 1,2- and 1,4-CHdiol, only $80 \%$ and $60 \%$ of the doses, respectively, were excreted in free and conjugated forms (2).

Regardless of the detailed mechanism of metabolic interactions between $\mathrm{CH}$-compounds and $\mathrm{EtOH}$, practical considerations can be drawn on the basis of the obtained results. While several authors suggested employing $\mathrm{CH}$-ol as a biomarker of the exposure to $\mathrm{CH}$ and $\mathrm{CH}$ one (3-5), we propose using $\mathrm{CH}$-diols alternatively or complementarily to $\mathrm{CH}$-ol. Our observation that the excretion of urinary $\mathrm{CH}$-diols is affected by $\mathrm{EtOH}$ much less than that of $\mathrm{CH}$-ol supports preferential use of $\mathrm{CH}$ diols as more reliable biomarkers of the exposure to $\mathrm{CH}$,
$\mathrm{CH}-$ one and $\mathrm{CH}-\mathrm{ol}$, especially in workplaces where alcoholic beverages are likely to be drunk.

\section{Acknowledgments}

This study was funded by research grant 0265-2 from the Internal Grant Agency of the Czech Ministry of Health, which is gratefully acknowledged.

\section{References}

1. Mráz J, Gálová E, Nohová H, Vítková D. Uptake, metabolism and elimination of cyclohexanone in humans. Int Arch Occup Environ Health 1994;66:203-8.

2. Mráz J, Gálová E, Nohová H, Vítková D. 1,2- and 1,4-Cyclohexanediol: major urinary metabolites and biomarkers of the exposure to cyclohexane, cyclohexanone, and cyclohexanol in humans. Int Arch Occup Environ Health. 1998;71:560-5.

3. Ong CN, Sia GL, Chia SE, Phoon WH, Tan KT. Determination of cyclohexanol in urine and its use in environmental monitoring of cyclohexanone exposure. $J$ Anal Toxicol 1991;15:13-6.

4. Perbellini L, Brugnone F. Lung uptake and metabolism of cyclohexane in shoe factory workers. Int Arch Occup Environ Health 1980;45:261-9.

5. Yasugi T, Kawai T, Mizunuma K, Kishi R, Harabuchi I, Yuasa J, et al. Exposure monitoring and health effect studies of workers occupationally exposed to cyclohexane vapor. Int Arch Occup Environ Health 1994;65:343-50.

6. Wilson HK, Robertson SM, Waldron HA, Gompertz D. Effects of alcohol on the kinetics of mandelic acid excretion in volunteers exposed to styrene vapour. $\mathrm{Br} \mathrm{J}$ Ind Med 1983;40:75-80.

7. Riihimäki V, Savolainen K, Pfäffli P, Pekari K, Sippel HW, Laine A. Metabolic interaction between m-xylene and ethanol. Arch Toxicol 1982;49:253-63.

8. Müller G, Spassowski M, Henschler D. Metabolism of trichloroethylene in man: III interaction of trichloroethylene and ethanol. Arch Toxicol 1975;33:173-89.

9. Cronholm T. Isotope effects and hydrogen transfer during simultaneous metabolism of ethanol and cyclohexanone in rats. Eur J Biochem 1974;43:189—96.

10. Ulirich V. On the hydroxylation of cyclohexane in rat liver microsomes. Hoppe-Seyler's Z Physiol Chem 1969;350:357—65.

11. Anonymous. Guiding principles for research involving animals and human beings: recommendations from the Declaration of Helsinki. Act Nerv Super 1982;31:159-60.

12. Flek J, Šedivec V. Identification and determination of metabolites of cyclohexanone in human urine [in Czech]. Prac Lék 1989;41:259-63.

13. Sakata M, Take J, Watanabe T, Sakata K, Wada K, Haga M. Metabolic interaction of ethanol and cyclohexanone in rabbits. J Toxicol Environ Health 1993;38:33-42.

14. Sellers EM, Lang M, Koch-Weser J, LeBlanc E, Kalant H Interaction of chloral hydrate and ethanol in man: I metabolism. Clin Pharmacol Ther 1972;13:37-49.

Received for publication: 28 July 1998 